\title{
Global Markets and Market-Space Competition
}

\author{
Silvio M. Brondoni*
}

\begin{abstract}
Globalisation imposes transition in the spatial competition relationships, specifically the abandonment of a competition domain coinciding with specific physical or administrative contexts (a product category, a country, a region, a geographical area, etc.).

Competition in global markets shapes a multi-dimensional space so that a given geographical context can imply the simultaneous presence of very different competitors.

Competition practices are further revolutionized, as they must take into account: saturated markets, and time-based competition.

Global markets with over-supply determine a new approach to competition, with a complete overturning of the hierarchy between customer satisfaction and manufacturing: goods are manufactured only when the level and amount of satisfaction required by customers is known.
\end{abstract}

Keywords: Market-Space Management; Global Markets; Over-Supply; Brand Equity; Brand Extension; Brand Portfolio; Franchising; Licensing; Cornering; Corporate Information Systems; Corporate Culture; System of Intangible Assets

\section{Global Markets and New Competition Boundaries}

The globalisation of markets highlights a deep re-thinking of long-term development philosophy by leading large corporations, that tend to reconcile a quantitative approach to growth (supply-driven management) with the goal of satisfying demand (market-driven management).

Indeed, a weak orientation toward demand can undermine the competitive strength of a business because of: excessive decision process centralization, progressive lack of sensitivity to local market opportunities, local 'bureaucratic' implementation of corporate strategies, damage to brand image ${ }^{1}$, deterioration of brand equity ${ }^{2}$.

Globalisation, in particular, imposes transition in the spatial competition relationships, specifically the abandonment of uni-dimensionality, that is the reference to a competition domain coinciding with specific physical or

*Full Professor of Management, University of Milan-Bicocca (silvio.brondoni@ unimib.it)

Brondoni Silvio M., Global Markets and Market-Space Competition, Symphonya. Emerging Issues in Management (symphonya.unimib.it), n. 1, 2002, pp. 28-42 
administrative contexts (a product category, a country, a region, a geographical area, etc.).

In global markets, traditional competition frameworks that focus on the simple sales expansion of certain products in some geographical areas, are thus abandoned. Quantitative development policies are replaced by strongly competitive 'customer satisfaction', which prevents fossilization in fixed product types and also stimulates an obsessive search for innovative matching of supply gaps and unsatisfied customer needs.

$\square$ For example, Ferrero is getting ever more global on strategies and market presence modes. $R \& D$ has always been global, and over the last decade purchases had already been organized according to a centralized model. Now, with the most recent organization, new forms of coordination have been devised, with a management structure for Europe and one for the rest of the world. Such reconfiguration will be better equipped to exploit: greater cost benefits and investments (both industrial and in ICT), innovation and integration in process development, inventory reduction, better ability to serve the commercial business units (Mark Up, July/August 2003).

Actually, competition in global markets shapes a multi-dimensional space so that a given geographical context can imply the simultaneous presence of very different competitors.

Moreover, competition practices are further revolutionized, as they must take into account: saturated markets, a situation of 'time-based competition', and finally, communication processes affecting sales and manufacturing. In this context the logic of competition becomes 'First Community, Second Business', that is 'sell first, then produce', with the overturning of traditional competition practices (typical of non-saturated markets, with slow imitation processes in which communication follows manufacture and sale) summarized in the 'First Business, Second Community' model, that is 'produce first, then sell'. In other words global markets with over-supply determine a new approach to competition, with a complete overturning of the hierarchy between customer satisfaction and manufacturing: goods are manufactured only when the level and amount of satisfaction required by customers is known.

The extended publishing industry (books, newspapers \& magazines, art publishing, CDs, films, etc.) features many examples of new competitive strategies - especially in the manufacturing/sale cycle caused by globalisation and e-commerce. A product, for example a book, is presented in 'web windows', but actually printed only after the customer has bought it. This eliminates unsold copies, returns and copies in the 'pipeline'. Moreover, volumes can be custom-made (with unprecedented flexibility and variety in terms of editions, format, colour, translations, etc.) Volumes are also immediately available (overcoming limits due to books being reprinted or out of stock) and can be manufactured anywhere, even a single copy. 
The mainly physical concept of competition space is therefore primitive and limited with respect to competition plans in which specific geographical contexts are assigned to express specific and partial competitive advantages (that is regarding manufacturing, marketing, $\mathrm{R} \& \mathrm{D}$, etc.) to be coordinated within a wider system of operations and profitability. The development of competitive space organisation is further confirmed by the drastic reduction in the competitive action/reaction times.

The expansion of the fronts of competition, and the need for an information system consistent with the reduction in decision-making times, in fact determine a competitive scenario that is very short term. Such a condition is especially emphasized by the widespread availability of electronic information flows, allowing dialogue (concerning products, prices, promotions, etc.) with many different parties, even simultaneously and in real time ${ }^{3}$.

Business development thus requires innovative spatial and temporal competition relationships, more precisely concerning:

- Extremely short decision-making times, in the context of 'time-based competition', with the elimination of bureaucratic inaction times.

- Competition spaces determined by the business attractiveness and ability to satisfy demand, and hence completely unconstrained by 'physical' geographical boundaries or local management's defined area of expertise.

In summary, global markets with over-supply force companies to face competition boundaries in which:

1. Space becomes a competition factor for businesses (market-space competition), with very dynamic and unstable features, due to the variability induced by continuous supply innovation and the increasingly selective character of demand.

2. The tangible character of supply and the administrative and geographical boundaries of the business area do not limit or restrict competition among businesses. On the contrary, corporate competitive behaviour is dominated by intangible supply features and by virtual spatial coordinates integrating and qualifying the physical dimension (market-space management).

\section{Over-Supply and the System of Intangible Corporate Assets}

In markets characterized by over-supply, 'tangible' product features are ever more standardized and do not allow for product differentiation. In such a context of final demand saturation, businesses are thus induced to assign value to non-basic modes of product fruition, thus affirming the predominance of intangible product aspects and new models of competition.

Indeed, in global markets businesses operate in different geographical areas with products that are quite differentiated, and therefore are able to assemble offerings with different ratios of intangible and tangible components. In practice, such ratios derive from specific competitive situations, approximately defined as: scarcity economies, economies with dynamic equilibrium between supply and demand, and finally over-supplied economies.

Scarcity economies $(D>S)$ show significant potential markets, with unsatisfied global demand, since the manufacturing capacity is not enough to satisfy the required volume. Moreover, the tangible aspects of products are dominant and 
quantity/quality can be assessed in terms of objective parameters. The customers' needs are elementary, well known and completely stable. Technological innovations are rare, and in any case timing and type are independent of competitive pressure.

On the contrary, economies characterized by dynamic equilibrium between supply and demand $(D \approx S)$ show efficient capacity for mass production and organized and aggressive sales organisations. The range of supply is wide, very segmented and focused on satisfying the range of expectations of potential customers. Many competitors offer products that are similar in basic functions and differentiated by accessory features. Demand is very non-homogeneous, with dissimilar expectations. Customer satisfaction depends on a multi-dimensional and unstable concept of 'overall value' of the offering. Such value combines tangible and intangible aspects and expresses a situation of equilibrium between supply and demand which is 'naturally' unstable, since it can be destabilized by the actions and reactions enacted by the various competitors to change knowledge and perceptions - and thus choices - for specific market demand segments.

Finally, over-supplied markets $(\mathrm{D}<\mathrm{S})$, show a structural excess in manufacturing capacity, that is goods manufactured with decreasing direct costs and significantly higher volumes than the potential of absorption by demand. In such contexts competition assumes a pressing pace, encouraged by a 'spiral effect' caused by rapid competitive imitation, acceleration of technological innovation processes and decreasing sale prices ${ }^{4}$.

Therefore, in markets with high competitive pressure, lasting business development does not depend primarily on the volume or the connotation of the specific products (easily imitated in terms of tangible aspects and with intangible product assets characterized by extreme volatility in marketing expenses). Indeed in global over-supplied markets, business success is determined instead by the level of presence and sophistication of the intangible corporate assets, i.e. the specific management skills concerned with the accumulated knowledge and the corporate system for gathering crucial information.

\subsection{Corporate Management and the System of Intangible Assets}

The intangible assets managed by businesses are related to: the promotion and strengthening of a specific organizational ${ }^{5}$ culture, the design and running of the corporate information system, and finally the creation and development of a specific brand equity.

The corporate intangible assets (brand equity, information system and corporate culture) actually form a tightly integrated system, that is one in which each of the intangible components draws its value from the others and is variously connected to them. Moreover, considering corporate intangible assets as a system implies that such a set is not just the sum of its elements, but is also made up of mutual interactions. Thus corporate culture, information systems and brand equity, when considered as the elements of a system, give value to the business to which they belong not only independently, but especially because they interact with one another. The structure we have described is shown in Figure 1, where the so-called system of corporate intangible assets is depicted. 
The system of intangible assets, made up of corporate culture, information systems and brand equity has the following key aspects:

- these intangible assets must be developed, maintained and if necessary changed by specifically targeted investments;

- intangibility certainly complicates representation, but does not exclude the need to assess the effectiveness of the investments dedicated to them in any way;

- intangible assets need time to be developed, and hence also the assessment of financial management choices made in the development;

- as part of a system, these assets cannot possibly maintain their state once they have been extracted from the context in which they were developed to be inserted in different systems of resources.

Figure 1: The System of Intangible Corporate Assets

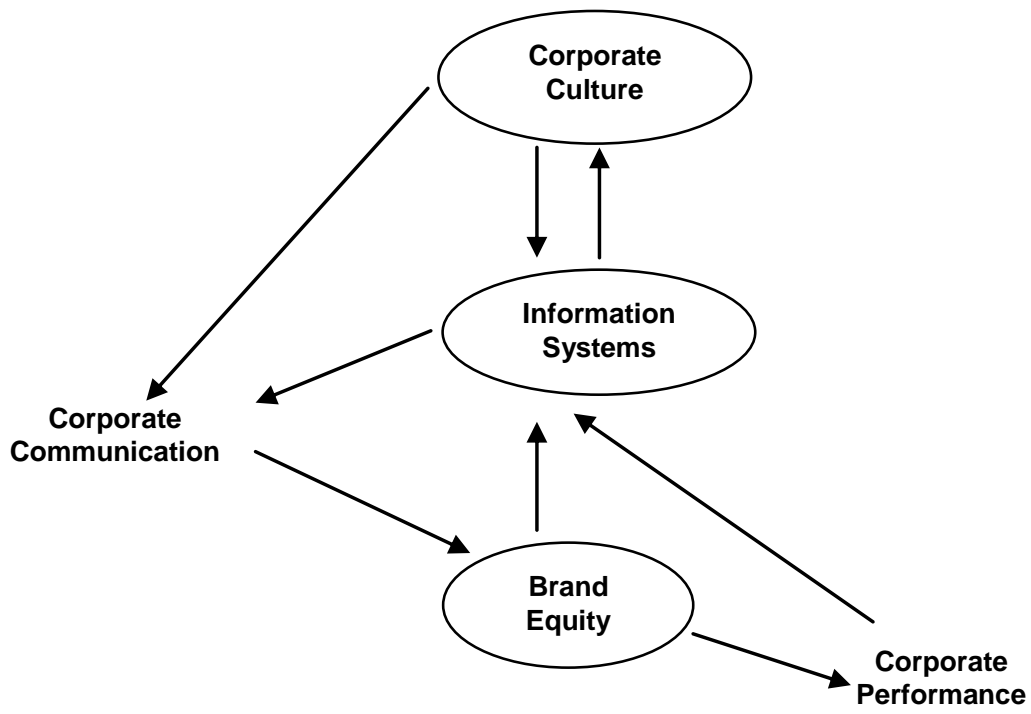

Source: S.M. Brondoni, M. Gatti, M. Corniani, Corporate Culture, Intangible Assets and Competition, ISTEI, Progetto Comunicazione Aziendale, cit.

This last observation highlights the central relevance of the interrelation among the intangible assets and explains the basic management principles of a corporate intangible asset system in a context of global markets without physical constraints to competition (market-space management).

Indeed, the intangible assets described above can be managed without any geographic operational constraints (hence, for example, a business can develop the same corporate culture in different countries) while they cannot be transferred to another business since only the tangible components of such assets are actually transferable. It is indeed possible to observe that:

1. brand equity: the only element that can be separated from a corporate context is the trademark. The trademark, which is the distinctive element of the company offering, is the tangible, identifying aspect of an offering, but is set apart from the value of the relationship (brand) established with a given market. Once transferred, a trademark identifies an offering by a different company: the new owners have to adjust their relationship with the market 
(brand) to its own specificity, thus developing different brand equity to the original;

2. corporate information systems: the tangible component is the computer system. This is made up of the equipment (hardware and software) and the architecture controlling it and can be replicated at will, but without any potential to recreate the same original intangible asset. The fact that it is used for the information needs of a new business determines a different use of the same equipment and involves different people, thus creating a new information system;

3. corporate culture can also not be separated from a business, not even by transferring real estate, key people, etc., even if these are important vehicles of the main characteristic cultural aspects. Acquiring the head office of a company or hiring its human resources does not allow its culture to be reproduced. When in contact with new internal and external players the same people will develop different forms and levels of synergy.

\section{Corporate Culture and Market-Space Management}

The critical role of corporate culture is particularly evident in large corporations, which for some time have faced globalisation and over-supply with corporate policies based on time-based competition and a competition space in which intangible potentialities play a crucial role (market-space competition). In this context of 'enlarged competitive space' the corporate culture develops within the business organization with a pervasive effectiveness, emphasized by the potentialities of new communication networks, such as: Internet (i.e. a public, world-wide, free-access network), Intranet (i.e. a private corporate network that can be used by employees only), Extranet (i.e. the extension of certain Intranet networks outside the company, to involve specific co-makers).

In complex organizations inclined to go outside the physical spheres of competition (market-space management) the importance of corporate culture in controlling the system of internal, external and co-makership relationships appears evident, since these relationships are based on close, extensive interactivity possible in real time without physical space constraints.

Indeed, the concept of corporate culture correlates to the concept of corporate personality and thus tends to permeate every expression and manifestation of the life of the organization, both within the organization and with the external environment.

In external relationships, personality influences the image of the company, which is how it is perceived by its various partners. Customers, shareholders, financial backers, public authorities, distributors, competitors, etc., can all form their own image of the business, based on the relationships set up and depending on their perception and cognitive frameworks. Image is the result of the processing of a system of signals by each individual partner, either sent directly or coming from other sources (media, competitors, consumers, financial backers, etc.), and allowing the attribution of value to company behaviour.

Internally, the establishment of a personality aiming at a high level of identification, allows the members of an organization to strongly align their goals, interests, values and conduct. Such alignment puts a system of guiding organization values into focus, leads to the acceptance of specific conduct rules and 
allows joint action for the achievement of common goals, evidently without the constraints and typical features (social, educational, ethnic, religious, etc.) of local organizations.

\subsection{Corporate Culture, Over-Supply and Manufacturing Location}

In global over-supplied markets, the critical role of corporate culture is especially evident in decisions concerning manufacturing location. Indeed, the situation of increasing manufacturing overcapacity at the international level induces businesses to adopt, in their choices of manufacturing location, highly competitive lines of conduct, specifically centred on:

- strategies for the development of the corporate 'cultural profile' as a competition factor. The policy of establishing a corporate personality, and bringing it out both within and outside the organization, is aimed at building a specific 'invisible asset'. Corporate culture thus becomes a crucial factor in enlarging the competitive space, since it allows moving the physical boundaries of manufacturing outside the firm (for example, by complementing the traditional manufacturing processes with outsourcing or networking policies), while at the same time keeping the identifying characters of brand equity under close control (manufacturing decentralization and exploitation of corporate brand equity);

$\square$ In businesses with a market-space management orientation, the attraction exerted by 'corporate brand' thus becomes dominant over the local 'career path' opportunities. In the same way staff rotation, planned and tied to incentives (regarding the timing and mode of entry/exit), replaces the traditional programs of continuing education (bound to static manufacturing units). Finally, compensation progression (previously based on seniority) is replaced by entry incentive plans and selective development plans, in which compensation is in proportion to the achievement of financial and quasi financial 'tasks'.

- strategies to increase brand equity value targeted at encouraging the 'corporate brand' and at the same time limiting the number of product brands, keeping in the corporate brand portfolio only those brands with customer awareness above the 'survival level' - and in any case easy to control by means of a structured information system so as to face international competition;

- 'up-sizing' strategies (through acquisitions, mergers, joint ventures and alliances) aimed at maintaining the manufacturing agreements with selected suppliers (co-makers) and especially with competitors. The establishment of more and more complex products and services (and the related value-added processes) transfers competition to the level of competing networks, as the competitive advantages derive from the integration of administrative functions going beyond the business boundaries of customers, manufacturers and suppliers ${ }^{6}$. 
Therefore in a situation of over-supply, manufacturing location choices mean abandoning the context of static, long term assessment, typical of proximity relationships between consumption and manufacturing. Similarly in the long term they do not depend on public location incentive policies, but instead give priority to the critical role of specific competition costs ( $R \& D$, local antitrusting, marketing, etc.), that are very sensitive for business management and development and introduce a new dimension in the space of manufacturing location related to highly dynamic assessments.

\section{Corporate Information Systems and Market-Space Management}

In businesses considering operating space as a competition factor (market-space competition), the corporate information systems are also a critical intangible asset with characteristics dependent on the prevailing culture within the organization ${ }^{7}$.

An extensive, changing operating space requires the continuous development of proactive interrelations and to this end information systems are the necessary tools for the critical assessment of potentialities and limits within and outside the organization. The processing of communication flows based on fully developed information systems allows for the continuous acquisition and spreading of news that interacts with the existent system of knowledge within complex business organisations.

In a context of market-space management, corporate culture actually becomes central in configuring the information system as a tool for controlling the internal and external communication flows. Therefore, it establishes - beyond geographic and administrative boundaries - the integration and adjustment guidelines allowing an organization to be on the same wavelength as the various environments in which it operates, within the context of a unique and non-duplicatable corporate identity ${ }^{8}$. In particular, information systems acquire remarkable importance in the management of so-called demand bubbles and the competition-oriented determination of prices (competitive pricing).

\subsection{Demand Bubbles and the Creation of Value}

Global over-supplied markets (generating increasing volatility in consumers preferences) deeply change the rules of the competitive game: products characterized by high marketing differentiation are indeed highly profitable only for organizations provided with the knowledge and the skills needed to intercept demand variability and thus continuously create consumption niches (demand bubble), be the first to satisfy them (time to market) and obtain a sizable profit by abandoning them in time (time competition), when the competitors-imitators arrive.

In global markets, over-supply can be an opportunity for development for those businesses that through unceasing product innovation know how to create and satisfy demand bubbles. That is, sectors of potential customers whose preferences converge on a certain offering for a limited time. These preferences, in any case, do not depend on specific geographic boundaries, but rather tend to put together the chance willingness to purchase by various groups (that are thus the basis on which 
the size of the bubble can be assessed at a certain time in a number of spaces) within the logic of market-space management.

Overcoming the physical boundaries to competition is also required by the continuous supply innovation: a business is caught between the opposing forces represented by customer satisfaction (oriented toward an increase in the value of goods at decreasing prices) and large scale competition, making growth in size a sort of prerequisite to continue competing.

The performance of global businesses is thus based on the ability to execute, on the part of management, the controlled fragmentation of demand and innovate while driven by customer satisfaction, regarding the expectations of potential customers in going beyond the traditional concept of market demand segmentation ${ }^{9}$.

Indeed, the market demand segmentation process (to meet the well-known conditions of being identifiable, reachable and measurable) presupposes segment stability over time and within the relevant competitive space. Therefore, manufacturing can decide to specialize in a given offering - thus fulfilling the expectations of a specific segment - only if demand is stable, that is, if it shows consumption behavioural modes that are constant and thus transferable to sales programs that are not likely to change much. The evidence is that such behavioural stability presupposes a high degree of purchase loyalty, which becomes the truly critical success factor.

In over-supply markets, instead, the stability of repetitive purchases is lacking, and the absence of loyal behaviour becomes more significant. In other words, there is a state of discontinuity driven by supply obsolescence and continuous product innovation, worked out on the basis of customer orientation (sensed by new tools and techniques such as competitive intelligence, data mining, loyalty cards, etc.). Existing demand is fragmented and recombined into unstable groups of purchasers, variously influenced by price but always very receptive toward information and communication.

\subsection{Purchase Loyalty and Non-loyalty}

In over-supply markets, structural manufacturing overcapacity generates a much higher volume of goods than the absorption potential by demand. However, the qualitative aspect of over-supply is even more dramatic for businesses, because the demand - by now used to having at its disposal a wide range of alternatives requires ongoing product range expansion.

The final purchasers, moreover, do not appear to be disoriented at all by manufacturers' accelerated pace of innovation (competition with ever more sophisticated goods at decreasing prices) but, on the contrary, themselves interfere in changing the purchase process through informed and opportunistic choices concerning purchase timing and mode. This is new purchasing behaviour in which the final customer tends no longer to be positioned at the end of the transaction chain, and is in a marginal, passive position prone to being affected by limited marketing investments. On the contrary, the purchaser is put into a 'circular relationship' with trade and manufacturers, and expresses new purchasing models based on new loyaltyless behaviour together with the well-known loyalty mechanisms. 
In practice, non-loyalty is expressed by a critical assessment of the value (and hence, first of all, the promise and credibility of the brand) of specific products, compared to the complete range of offerings of specific points of sale at certain times. Purchase decisions can thus be radically changed in timing and/or in space or be late in manifesting themselves, with postponement of the purchase - as they try to optimise mutable information about the differential value of the good (brand benefit) and, at the same time, about the specific benefits of the point of purchase (outlet benefit).

Non-loyalty compromises the inertial mechanisms typical of loyalty (brands with stable value, available at a limited number of points of sale) and induces manufacturers and trade to activate loyalty building programs, which go after nonloyal demand with tempting proposals, build a dynamic purchase relationship (stop \& go) to be channelled into a system or real and virtual points of sale, both integrated into the context of 'market-space competition'.

Loyalty building thus exploits the profitable but volatile benefits typical of nonloyal relationships, and for this reason requires massive investments. These must be in information systems and the development of intangible product aspects (brand responsibility, product design, merchandising). Retailers must instead redesign buildings to emphasize the value of offerings based on non-loyal relationship models (like offering, for example, sports cars at a fast-food corner) but must above all invest in the intangibles of a 'personality store' (physical and virtual location, opening days and hours, pre- and after-sales service, staff training).

\section{Brand Equity and Market-Space Management}

Finally, firms can go beyond the geographical and administrative boundaries of competition (market-space management) by exploiting solid brand equity. Brand equity is the synthesis of the effects of communication for the development of a brand's market relationship, and thus also defines the state of the competitive edge of the business in specific markets.

In a context of 'market-space competition', brand equity can be exploited to overcome the physical limits of competition from different points of view, in some cases focusing on the potential value of specific brands (for example, through brand extension or brand portfolio strategies), and in other cases focusing on the strength of a brand for the development of the whole business (typically through franchising, licensing and cornering strategies).

\subsection{Brand Extension and Brand Portfolio}

The most elementary form of enlargement in competition boundaries, (marketspace competition), based on specific offerings and explicitly referring to brand equity, is 'brand extension', that is the extension of a brand, already established in a certain product category, to different product classes. Brand extension policies are a 'natural' strategy space expansion for businesses pursuing corporate development through the exploitation of intangible corporate assets into new business areas (product categories). 
$\square$ At the beginning of the eighties, Levi Strauss (a company with sales of about US\$ 2 billion and with high market share in several product categories) began a process of enlargement of its competitive space in its markets, to continue corporate development. A brand extension policy was implemented to this end, and gradually expanded over time to become worldwide, under the guidance of an in-depth study of consumer needs ${ }^{10}$.

A more sophisticated and costly form of competition boundary enlargement (market-space competition), still based on brand equity of specific business offerings, can be developed by resorting to the brand portfolio.

Indeed in the most evolved economic systems, in a situation of over-supply, demand is fractioned into many needs (both functional and symbolic) that cannot be satisfied by a single 'promise', that is by the system of responsibilities represented by a single brand. This context of supply-demand relationships, much differentiated in the corporate competitive space, allows operating with a brand portfolio including a specific brand for each demand category.

The characterization of a brand portfolio in the enlargement of the competition space is related to several opportunities. First of all, a large number of brands can be needed to contribute to the 'building of a market'. Indeed, an individual offering is hardly able to satisfy sizable, fully developed demand. Moreover, a multi-brand portfolio policy makes it possible to compete with many brands in the same market, and hence allows marketing of the lower profile brands for tactical purposes (for example, to limit the competitors' potential for brand extension) so as to defend the brand from discount policies that could undermine the image of the leading brand. Finally, a multi-brand portfolio policy can be necessary to satisfy the specific needs of regional markets, or spatially defined geographic and administrative contexts (as in the case of the large international beer manufacturers) ${ }^{11}$.

\subsection{Franchising, Licensing and Cornering}

The enlargement of physical competition spaces can also be obtained by a business considered as a whole organization that is without referring to specific offerings, but instead concerning brand equity referred to a certain corporate brand. The typical tools to achieve this are franchising, licensing and cornering.

The well-known franchising systems are networks of businesses in which a central organisation (franchiser) is connected to satellite organizations (franchisees) by financial and contractual co-makership relationships. The franchisees are hence management independent within a specific entrepreneurial group scheme. Even in its simplest form, franchising allows participation (usually with exclusive rights for a certain offering) in a manufacturing and distribution formula which of its own nature transcends the traditional constraints to competition.

Moreover, in a situation of over-supply the typical flexibility in franchising acquires further relevance and becomes invaluable for development. Indeed, in over-supply markets, the importance of the benefits related to location and geographic exclusive rights drastically decreases, while peculiar intangible competition factors become critical: for example, brand awareness (and thus the 
size and continuity of the promotional investments), the structure and differentiation of the type of offering by the franchisees (to optimise the volumes sold, unsold and un-sellable), the consistency between brand image and the integrated franchisee communication policy, and finally the sophistication of the information and coordination tools, especially for the development of corporate behaviour, values and culture.

The overcoming of physical constraints to competition can also be pursued through licensing, that is the temporary transfer of the rights to use a trademark ${ }^{12}$. In recent times, licensing has actually been limited to the commercial exploitation of well-known trademarks to extend the distinctive business area with additional returns. In this context, the right to use a trademark is transferred to the highest possible number of users, even in heterogeneous industries usually unconnected with opportunities for brand development.

Today licensing can be more appropriately considered as a business aimed at increasing brand equity and especially as a tool to expand the competitive value of brand image and awareness in industries not coinciding with a company's core business. Therefore, in highly competitive contexts, the potential to obtain royalties from the exploitation of a known trademark is completely subordinate and accessory with respect to the opportunity to develop brand equity ${ }^{13}$. For example, according to this intangible competitive space enlargement strategy, the transfer of the right to use a car trademark to companies manufacturing mobile or fixed phones, etc., could happen only if it led to an upgrading of the value of the base trademark quantifiable by suitable value parameters.

Finally, the corporate competitive space can also be expanded through cornering: the transfer from a retailer to a manufacturer of sales space (or more precisely conditions), thus generating synergic action between the retailer and manufacturer's brands. Cornering, in its most traditional form, allows both retailers and manufacturers to enlarge their respective competition boundaries. In particular, manufacturers can be present at airports, exhibitions, stations, roadside restaurants, etc., that is, at locations frequented by an enlarged target group of final consumers. For retailers, cornering allows for the exploiting of benefits in image for the singlebrand retail points, and at the same time for a reduction in investments and risks that is characteristic of fully owned stores, especially in the launch of new products.

Barilla signed a strategic partnership with Tank\&Rast (a German group active in roadside restaurants) to open 'Barilla -pasta corners' at 110 service stations along the German motorways. Tank\&Rast will provide suitable logistic support, while Barilla will manufacture a specially designed line of pasta and sauces (Corriere della Sera, 22nd March 2003).

$\square$ The Faber-Castell group, the world's leading manufacturer of pencils, (1.8 billion pieces per year, 5,000 employees, sales of $€ 305$ million) started a cornering initiative in the most significant stationery stores with diversification toward leather articles (Il Mondo, 27th September 2002). 
$\square$ Sagit, a Unilever Group company, invested massively in the 'bar and restaurant' channel, where it controls 50\% of the market, for the launch of 'soft gelato' in Italy. Sagit distributed 24,000 dispensers and as many special fridges for the new 'soft' product (which is kept at -10 degrees instead of the -18 normally required by ice-cream), thus creating a specific corner for its new line (Il Mondo, 1st August 2003).

In a situation of over-supply, cornering can also define new competition boundaries (market-space competition) between retailers and manufacturers and through more innovative forms referred to as virtual cornering. These agreements still require a contract and the negotiation of conditions for the presence of the manufacturer, a guaranteed minimum, a proportional commission on sales and contract duration with fixed and renewable termination. They extend toward forms of intangible competition - for example through multi-media stalls, web windows, data base mailing, etc. - and thus contribute to delineating new industry/distribution relationships, especially with new connections between sales and pre- and after-sales service, as appears to be happening in Europe for multibrand dealerships in the automotive sector.

\section{Bibliography}

Aaker D.A., Managing Brand Equity, The Free Press, New York, 1991.

Albanese Fabio, Merchandising and Licensing to Improve Brand Equity. The Coca-Cola Case, Symphonya. Emerging Issues in Management (symphonya.unimib.it), n. 1, 2000-2001. http://dx.doi.org/10.4468/2001.1.06albanese

Brondoni Silvio M. (ed.), Marketing Lexicon, CLUEB, Bologna, 1999.

Brondoni Silvio M., Gatti Mauro, Corniani Margherita, Cultura d'impresa, ‘intangible assets’ e modelli di concorrenza, Progetto Comunicazione Aziendale - Research Report, ISTEI-University of Milan-Bicocca, January, 2001.

Brondoni Silvio M., Brand Policy and Brand Equity, Symphonya. Emerging Issues in Management (symphonya.unimib.it), n. 1, 2000-2001. http://dx.doi.org/10.4468/2001.1.02brondoni

Brondoni Silvio M., Gatti Mauro, Corniani Margherita, Competizione globale, risorse immateriali e responsabilità sociale d'impresa, 25th AIDEA Workshop, Novara, October 4-5, 2002.

Brondoni Silvio M., Comunicazione, performance e sistema delle risorse immateriali d'impresa, Sinergie, n. 59, 2002.

Cappelletti M., Alleanze strategiche: la cooperazione interaziendale come alternativa alla fusione, Graphicus, April, 2003, p.10.

Schuiling Isabelle, Think local - Act Local: Is It Time to Slow Down the Accelerated Move to Global Marketing?, Symphonya. Emerging Issues in Management (symphonya.unimib.it), n. 1, 2000-2001.

http://dx.doi.org/10.4468/2001.1.08schuiling

\section{Notes}

1 'The brand, representing the relationship developed between supply and demand, is in a central position with respect to a complex system of information flows, some going from the demand (or 
more generally from the external environment) to the business, others going from the business to the demand and the environment (corporate communication). The brand is located at the centre of this system of flows and develops by virtue of them, being the outcome of a continuous process of action/reaction joining the corporate reality (resources, goals, values, etc.) to the external market context and in general to the environment'. See S.M. Brondoni, M. Gatti, M. Corniani, Competizione globale, risorse immateriali e responsabilità sociale d'impresa, $25^{\circ}$ AIDEA Workshop, Novara, 4-5th October 2002.

2 'Brand equity, that is the state of the brand relationship at a certain time, is the asset originating from the system of internal and external information flows, and is connected to corporate performance in a competitive context. Indeed a business endowed with definite brand equity emerges in competition as the bearer of connotations that are specific (brand image) and known (brand awareness) allowing it to occupy a privileged position compared to other businesses'. See S.M. Brondoni, Brand Policy and Brand Equity, Symphonya. Emerging Issues in Management (symphonya.unimib.it), n. 1, 2000-2001.

${ }^{3}$ See S.M. Brondoni, Comunicazione, performance e sistema delle risorse immateriali d'impresa, Sinergie, n.59, 2002.

${ }^{4}$ The situation of over-supply thus delineates new competition mechanisms, with a deep rethinking of the theories about business management and economy. On the other hand, these had been developed in very different supply and demand contexts. The basic principles of 'rational business management' have indeed been developed to 'guide' a demand that was higher than the supply (scarcity economy phase, characterizing the United States until the forties and Italy until the end of the fifties). Later, the evolution of the international situation introduced new paradigms of business management, aimed at stimulating demand in continuous dynamic equilibrium with supply (welfare state phase, which lasted internationally until the end of the eighties).

5 See S.M Brondoni, M. Gatti, M. Corniani, Cultura d'impresa, 'intangible assets' e modelli di concorrenza, in Progetto Comunicazione Aziendale, ISTEI-Istituto di Economia d'Impresa, Università degli Studi di Milano-Bicocca, January 2001.

${ }^{6}$ The role of inter-business cooperation is becoming more and more important in the graphics industry... companies developing 'higher order' business structures through very flexible structures depending on the project at hand can reach an operational level characterized by high value added.. The tasks of research, development, and manufacturing and especially the management of the projects are assigned to the various companies on a case-by-case basis, and limited in time by the so-called 'virtual company'. See M. Cappelletti, Alleanze strategiche: la cooperazione interaziendale come alternativa alla fusione, Graphicus, April 2003, p.10.

7 'To consider the information system as an asset means to recognize its contribution to the corporate performance, that is its role in controlling the flow of information that is the nourishment of management. Regarding brand equity, for example, the information system activates and controls the information flow coming from the external world (such as demand, competition, legislative bodies) and at the same time is the tool allowing for the spread of such information within the company; in this way it becomes possible to make decisions aimed, in turn, at orienting the outgoing information flows (corporate communication) and further incoming flows (specific information gathering, competitive intelligence, market studies and marketing surveys). In this sense, for businesses, the information system represents the ability to acquire, process and spread a high information flow targeted at maintaining and/or developing a well defined relationship between supply and demand (brand) and hence specific brand equity'. See S.M. Brondoni, M. Gatti, M. Corniani, Competizione globale, risorse immateriali e responsabilità sociale d'impresa, op. cit.

${ }^{8}$ Corporate culture thus confers a unitary character, related to a specific corporate identity, in the information system. For example, depending on the consensus management model adopted, the information system can be characterized by free and widespread accessibility, or rigid preset fruition paths. Also the prevailing propensity to risk and timescale orientation of a business (typical aspects of the corporate culture) will influence the corporate information system. For example, by determining which phenomena must be constantly monitored and in defining the timing of the feedback information. 
9 Market demand segmentation marked the transition from scarcity proto-economy (D>S, characterized by a much higher demand than the supply, so that all that is manufactured is certainly sold) to more complex competitive conditions, with an unstable equilibrium between supply and demand $(D \approx S$, the so-called welfare state). The situations of dynamic instability determine the presence of various specialized and lasting classes of demand (segments) in certain geographical areas; each segment aims at satisfying specific customer needs (for example, concerning cars, the primary need for private transportation - characteristic of scarcity economies - expands - in welfare state markets - into a range of 'secondary functions', like sedan, station wagon, coupe, roadster, etc.).

${ }^{10}$ See D.A. Aaker, Managing Brand Equity, The Free Press, New York, 1991, pp. 206.

${ }^{11}$ On the system of international, national and local brands of the Heineken and Carlsberg groups see: S.M. Brondoni, Brand Policy and Brand Equity, cit.; I. Schuiling, Think local - Act Local: Is It Time to Slow Down the Accelerated Move to Global Marketing?, Symphonya. Emerging Issues in Management (symphonya.unimib.it), n. 1, 2000-2001.

${ }^{12}$ Licensing (transfer of the rights to use a trade-mark) is a management technique started and established in the United States, based on the market strength of a brand, that is the most elementary intangible aspect of a product. Licensing is an international competition strategy more sophisticated than licencing (sale of products under license), which had been previously developed - especially by British companies with extended and branching commercial interests in the British empire - for tangible products, with the aim of expanding manufacturing through partnership and co-makership in controlled developing areas. See S.M. Brondoni (ed.), Marketing Lexicon, CLUEB, Bologna, 1999, pp. 187 e 372.

${ }^{13}$ See F. Albanese, Merchandising Merchandising and Licensing to Improve Brand Equity. The Coca-Cola Case, Symphonya. Emerging Issues in Management (symphonya.unimib.it), n. 1, 20002001. 